\title{
The role of dorsal vs ventral striatal pathways in cocaine-seeking behavior following prolonged abstinence in rats
}

\author{
R. E. See • J. C. Elliott • M. W. Feltenstein
}

Published online: 19 September 2007

(C) Springer-Verlag 2007

In this paper the concentrations of baclofen and muscimol as listed in the methods were inadvertently reversed. The correct concentrations are: baclofen $=1.0 \mathrm{mM}$ and muscimol= $0.1 \mathrm{mM}$.

The online version of the original article can be found at http://dx.doi. org/10.1007/s00213-007-0850-8.

R. E. See $(\bowtie) \cdot$ J. C. Elliott $\cdot$ M. W. Feltenstein

Department of Neurosciences,

Medical University of South Carolina,

173 Ashley Avenue,

Charleston, SC 29425, USA

e-mail: seere@musc.edu 